\title{
Endoscopic treatment of rectal pocket syndrome
}

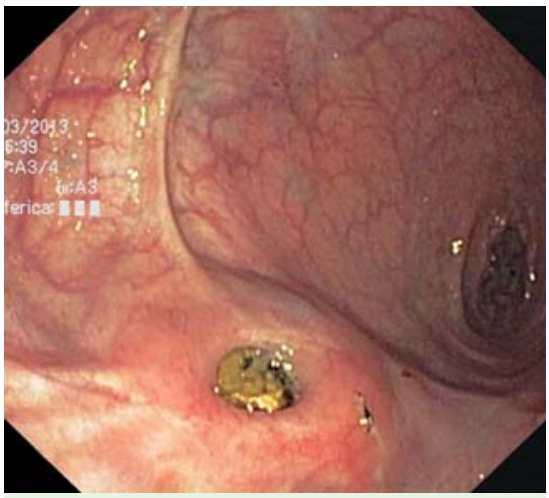

Fig. 1 Rectal bulge with central orifice.

A 70-year-old woman was admitted with rectal pain and soiling 3 years after a Longo's stapled hemorrhoidopexy [1]. Physical examination and laboratory tests were negative. Colonoscopy showed a $30-\mathrm{mm}$ bulge with a $3-\mathrm{mm}$ orifice in the lower rectum. Stools could be observed through the orifice ( Fig.1). A pelvic magnetic resonance imaging scan highlighted a stool-laden diverticulum of the mesorectal region, $35 \times 20 \times 25 \mathrm{~mm}$ in size ( Fig.2). An endoscopic ultrasound color-Doppler examination showed poor vascularization of the septum between the diverticulum and the rectal lumen.

Endoscopic incision of the cavity wall was performed using a biliary pre-cut needle, with incisions at 3,6, and 9 o'clock ( Fig.3). Stools were then evacuated by digital squeezing. The procedure was complicated by bleeding, which was successfully treated by endoscopic clipping.

The patient was discharged after a brief observation period. At 1-month followup she was asymptomatic, and lower endoscopy showed a fully opened diverticulum with no residual stool ( $\bullet$ Fig.4).

The "rectal pocket syndrome," caused by entrapment of the tied purse string by fired staples, is a rare complication $(2.5 \%)$ of stapled hemorrhoidopexy and usually requires surgical opening of the pocket [2]. Only two case reports have been published previously in the literature, one of which was managed by releasing the tied suture and the other by creating a divert-

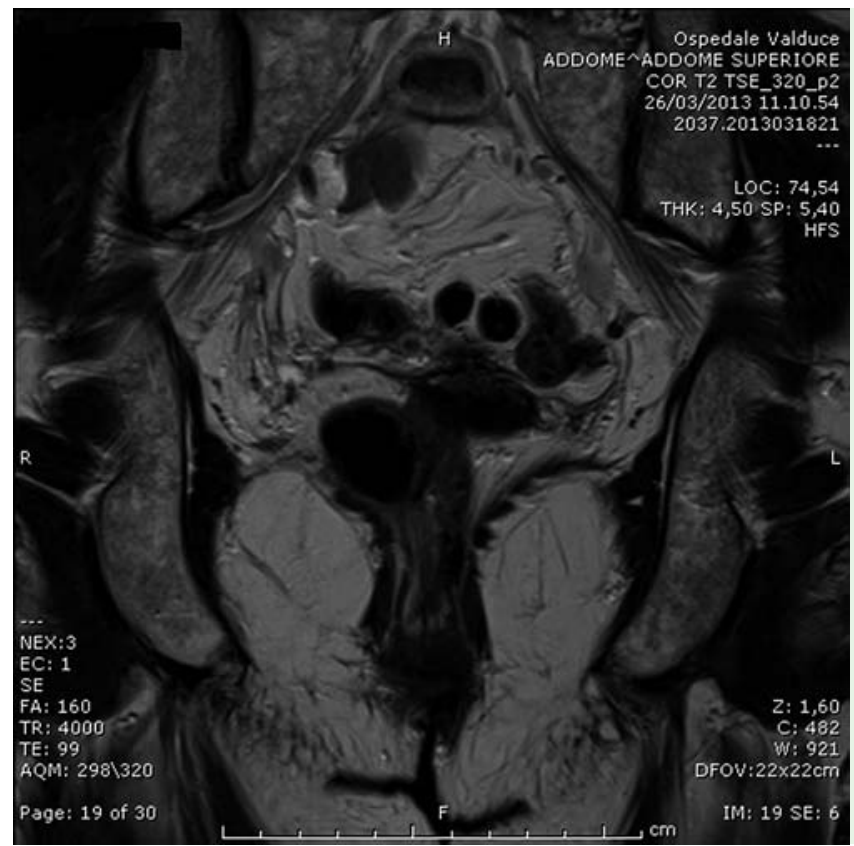

Fig. 2 Pelvic magnetic resonance imaging showed a stool-laden diverticulum in the mesorectal region.

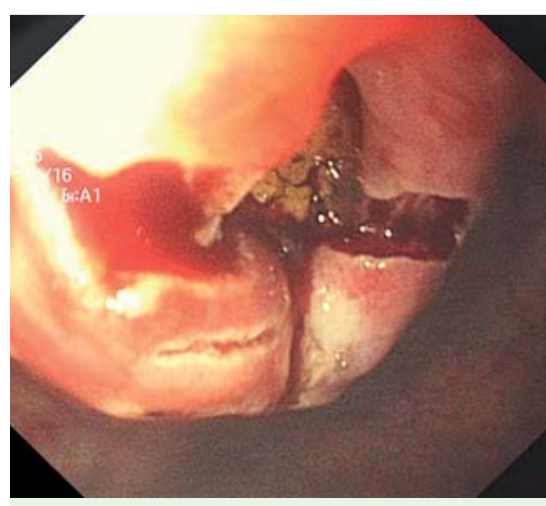

Fig.3 Endoscopic incision of the cavity.

ing stoma $[3,4]$. To our knowledge the present case is the first report of endoscopic treatment for rectal pocket syndrome. The procedure appears to be feasible, safe, and effective. The idea was taken from experience of treatment of esophageal rings by means of sagittal incision [5].

\section{Endoscopy_UCTN_Code_TTT_1AQ_2AJ}

Competing interests: None

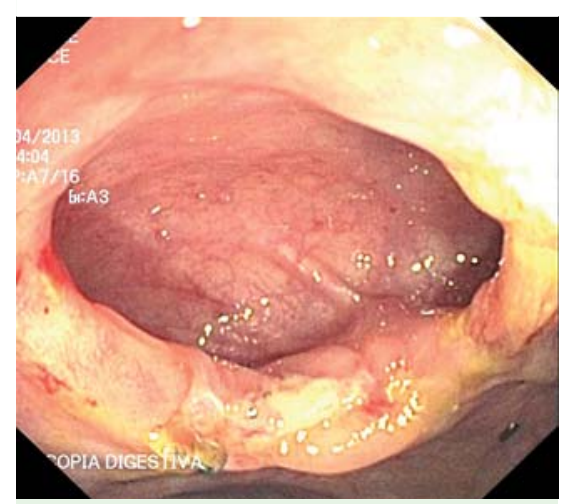

Fig. 4 The fully opened diverticulum (1 month follow-up).

\section{A. Amato ${ }^{1}$, A. Vannelli ${ }^{2}$, F. Radaelli ${ }^{1}$,} S. Paggi ${ }^{1}$, E. Rondonotti ${ }^{1}$, G. Spinzi ${ }^{1}$

${ }^{1}$ Division of Gastroenterology, Valduce Hospital, Como, Italy

2 Division of Surgery, Valduce Hospital, Como, Italy 


\section{References}

1 Longo A. Treatment of haemorrhoidal disease by reduction of mucosal and haemorrhoidal prolapse with a circular-suturing device: a new procedure. In: Proceedings of the 6th World Congress of Endoscopic Surgery; 1998 June 3-6; Rome, Italy. Rome: Monduzzi Editori; 1998: 777-784

2 Pescatori M, Aigner F. Stapled transanal rectal mucosectomy ten years after. Tech Coloproctol 2007; 11: 1-6
3 Cipriani S, Pescatori M. Acute rectal obstruction after PPH stapled haemorrhoidectomy. Colorectal Dis 2002; 4: $367-370$

4 Da Rin F, Faccini M, Pinardi $L$ et al. An uncommon complication after rectal mucosal prolapsectomy. Osp Ital Chir 2006; 12: 214-216

5 DiSario JA, Pedersen PJ, Bichiș-Canoutas C et al. Incision of recurrent distal esophageal (Schatzki) ring after dilation. Gastrointest Endosc 2002; 56: $244-248$

\section{Bibliography}

DOI http://dx.doi.org/ 10.1055/s-0033-1344419

Endoscopy 2013; 45: E282-E283

(c) Georg Thieme Verlag KG

Stuttgart · New York

ISSN 0013-726X

\section{Corresponding author}

A. Amato, MD

Divisione di Gastroenterologia

Ospedale Valduce

Via Dante 11

22100 Como

Italy

Fax: +39-031-308047

arnalam@alice.it 